\title{
DEVELOPMENT OF LEVEL 2 CALIBRATION AND VALIDATION PLANS FOR GOES-R;
}

WHAT IS A RIMP?

Thomas J Kopp, Leslie O Belsma, Andrew K Mollner, Ziping Sun, Frank De Luccia

The Aerospace Corporation, EI Segundo, CA
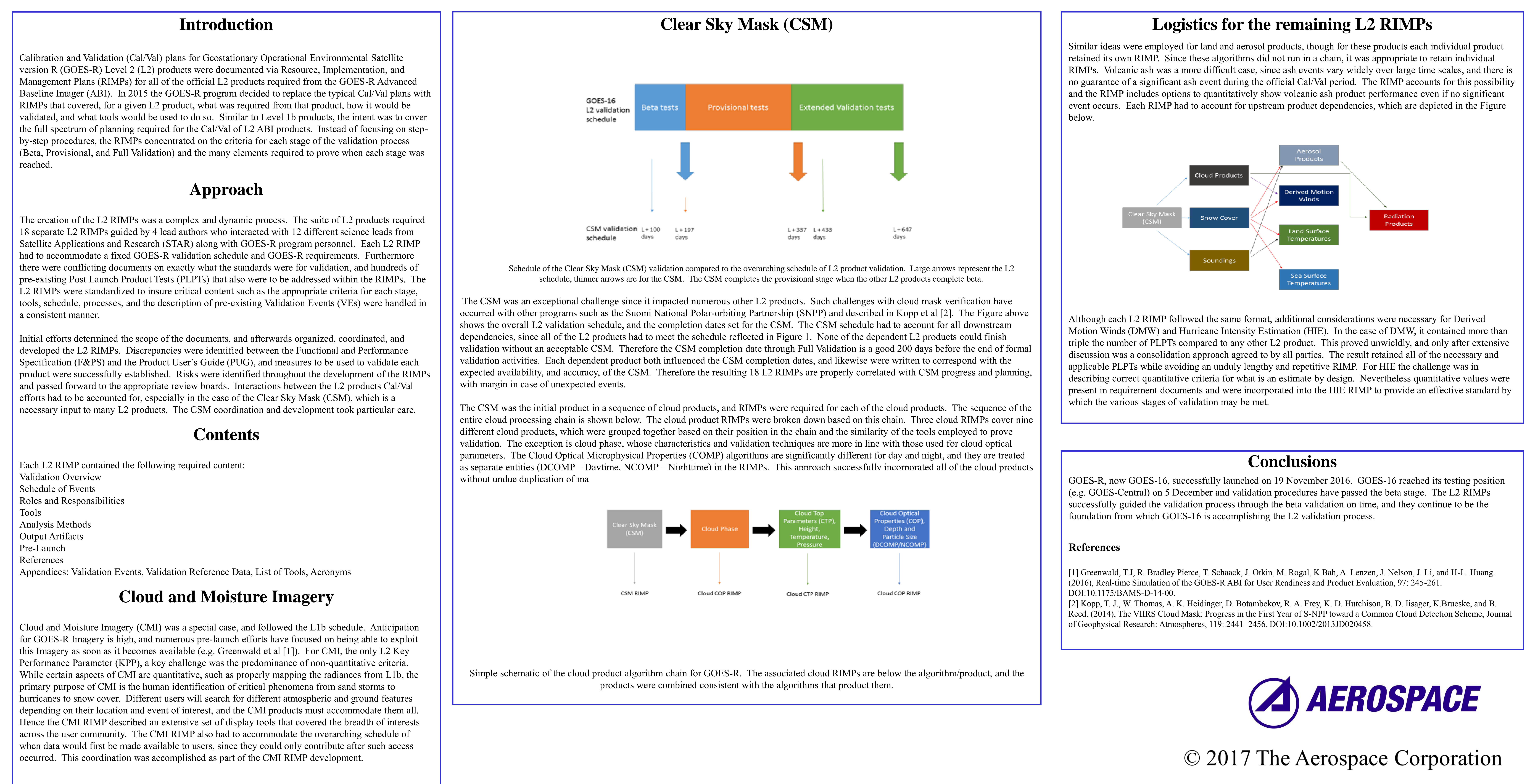

\section{(J) AEROSPACE}

(C) 2017 The Aerospace Corporation 